\title{
A implantação do currículo baseado em competência na graduação de fisioterapia: a integralidade como eixo condutor
}

\author{
The deployment of the competency based curriculum in undergraduate \\ physiotherapy: the integrality as the driver axis
}

Camila Sotello Raymundo¹, Deborah Varjabedian¹, Maria Elisabete Guazzelli', Marco Akerman²

'Universidade Anhembi Morumbi (UAM) - São Paulo (SP), Brasil.

${ }^{2}$ Faculdade de Medicina do ABC (FMABC) - Santo André (SP), Brasil.

DOI: http://dx.doi.org/10.7322/abcshs.v40i3.799

\section{RESUMO}

Introdução: Na busca de um novo perfil para o fisioterapeuta, há a necessidade de reformular a formação de profissionais fisioterapeutas que atendam a uma nova demanda. Este estudo busca apoiar-se nas premissas da interdisciplinaridade na organização dos conhecimentos e o desenvolvimento de práticas e ações que buscam a integralidade na atenção a saúde entre os docentes do curso de graduação de fisioterapia de uma Universidade Privada e Internacional aqui estudada, por meio de um currículo baseado em competências. Objetivo: Identificar as dificuldades e as facilidades da implantação de um currículo por competências no curso de Fisioterapia, orientado pela Integralidade. Métodos: Neste percurso, utilizamos como método a Pesquisa-Ação, como estratégia para a investigação da eficácia da implantação do currículo integrado e os atores envolvidos foi o corpo docente. Resultados: Durante o processo de implantação do currículo foi possível entender que um currículo baseado por competências é flexível, permite mudanças, de acordo com as necessidades atuais. Conclusão: Conclui-se que um currículo integrado permite sempre novas inserções, com possibilidade de ouvir e empoderar os docentes neste processo, que são essenciais para o sucesso na implantação de um currículo baseado em competências.

Palavras-chave: integralidade em saúde; ensino; fisioterapia.

\section{ABSTRACT}

Introduction: In search of a new profile for the physiotherapist, there is a need to reformulate the formation of professional physiotherapists that meet the new demand. Thus, this study seeks support on assumptions of interdisciplinarity in the organization of knowledge and the development of practices and actions that seek comprehensiveness in health care between the faculty of the physical therapy course at an international and private university, here studied, by means of a competency based curriculum. Objective: To identify the sorrows and delights of the deployment of a competency based curriculum in Physical Therapy course, guided by integrality. Methods: In this course, we use the method Research-Action as a strategy for the investigation of the effectiveness of the deployment of the integrated curriculum and the actors involved on this study were professors (core) from a course of Physiotherapy in international and private University. Results: During the deployment process of the curriculum was possible to understand that a competency based curriculum is flexible, allows changes, according to the current needs. Conclusion: It is concluded that an integrated curriculum allows always new insertions, and is possible, as well, to listen and to empower teachers in this process because they are essential to the success in the deployment of a competency based curriculum.

Keywords: integrality in health; teaching; physical therapy specialty. 


\section{INTRODUÇÃO}

A ideia deste artigo partiu da necessidade de aplicar os conceitos de integralidade de atenção à saúde no cenário da educação superior em fisioterapia, nas Instituições particulares para a efetivação de um currículo por competências.

A integralidade traz uma rede de significados tão amplos e passivos de diferentes interpretações que seu entendimento, desde o início, configura como um grande desafio para a composição desta tese.

A educação no Brasil de hoje por si só já é um tema amplo e de muitas discussões; pensar na formação acadêmica sob uma nova perspectiva, com novas metodologias de ensino e um currículo por competências, ministrado por docentes que tem sua base formativa no ensino tradicional é um desafio que requer mais do que muito estudo, leitura e investigação, requer também a responsabilidade e o compromisso com a mudança.

Desde 2007, o curso de fisioterapia que compõe a Universidade aqui estudada, vem sofrendo grandes mudanças no que tange as estratégias de ensino, incluindo a inserção de metodologias ativas de ensino, mudanças nas grades curriculares e a busca da excelência na formação do aluno voltado à saúde coletiva. O processo que envolve esta mudança é lento, pois engloba transformações não só na organização dos fazeres, mas também dos saberes.

A incorporação da interdisciplinaridade na organização dos conhecimentos, buscando um currículo baseado em competências e o desenvolvimento de práticas e ações que buscam a integralidade na atenção à saúde são mudanças profundas e extensas que exigem constante reavaliação, novas análises e a tomada de novas medidas em busca da excelência na formação superior.

As crises econômicas, políticas e, sobretudo de sentidos e valores tem assolado estados, comunidades e frontalmente a educação e a cultura, na educação superior, especialmente pela responsabilidade dessa instituição em produzir, fomentar e disseminar conhecimentos, técnicas e habilidades uteis ao desenvolvimento das condições de possibilidades da economia global ${ }^{1}$.

A Fisioterapia é uma atividade de saúde, regulamentada pelo Decreto-Lei 938/69, Lei 6.316/75, Resoluções do Coffito, Decreto 9.640/84, Lei 8.856/94².

O Conselho Federal de Fisioterapia (Coffito) define Fisioterapia como uma ciência da Saúde que estuda, previne e trata os distúrbios cinéticos funcionais intercorrentes em órgãos e sistemas do corpo humano, gerados por alterações genéticas, por traumas e por doenças adquiridas. Fundamenta suas ações em mecanismos terapêuticos próprios, sistematizados pelos estudos da Biologia, das ciências morfológicas, das ciências fisiológicas, das patologias, da bioquímica, da biofísica, da biomecânica, da sinergia funcional, e da cinesiopatologia de órgãos e sistemas do corpo humano e as disciplinas comportamentais e sociais².

O Fisioterapeuta é um Profissional de Saúde, com formação acadêmica Superior, habilitado à construção do diagnóstico dos distúrbios cinéticos funcionais (Diagnóstico Cinesiológico Funcional), a prescrição das condutas fisioterapêuticas, a sua ordenação e indução no paciente bem como, o acompanhamento da evolução do quadro clínico funcional e as condições para alta do serviço².

Inicia-se neste momento refletindo sobre a definição do Coffito de "distúrbios cinético funcionais", observa-se que ela parte do princípio da doença como fator preponderante da atuação do fisioterapeuta. Em muito, o perfil profissional do fisioterapeuta é construído a partir dessa perspectiva reducionista.

Incompleta e superada, essa definição está assim construída muito provavelmente porque, até a década de 1980, a atuação do fisioterapeuta estava restrita à recuperação e à reabilitação, centrada, portanto na lógica da "doença” e da "incapacidade”. Razões lógico-históricas originaram a regulamentação dessa prática como profissão, em particular o pós-guerra dos anos 1940. Essa conjuntura conduziu a Fisioterapia para a valorização excessiva da doença, associando a profissão a uma visão curativa, além de desenvolver práticas distantes da interlocução com outras profissões ${ }^{3}$.

É a partir dos anos 1980 que a formação em Fisioterapia, por meio da redefinição de seu objeto de trabalho e de estudo, passa a incorporar a promoção e a prevenção da saúde da população como área de atuação ${ }^{4}$. Desde então, os cursos de Fisioterapia têm incorporado, ora mais ora menos, a prevenção e a promoção nas suas estruturas curriculares.

Reflexões à cerca de saúde e doença de Canguilhem e Winnicott buscam uma definição que se afasta da racionalidade científica do pensamento biomédico clássico que busca "corrigir" os fenômenos vitais, em direção a um modelo contemporâneo onde matéria e cultura, mente e corpo fazem parte da mesma natureza. Assim, o conceito de saúde se expande na intensidade das forças vitais, sem ser compreendida como o oposto da doença ${ }^{5}$. O campo da saúde coletiva busca descrever "O processo de definição e identificação dos problemas de saúde como uma negociação complexa entre vários atores, cujos resultados são contingentes e instáveis ao longo do tempo"'.

A convicção da medicina em poder restaurar cientificamente o normal é tal que acaba por anular o patológico ${ }^{7}$. A doença deixa de ser objeto de angústia para o homem são e torna-se objeto de estudo para o teórico da saúde. E é justamente no patológico, segundo seu pensamento, que se pode decifrar o ensinamento da saúde, de certa maneira como "Platão procurava nas instituições do Estado o equivalente, ampliado e mais facilmente legível, das virtudes e vícios da alma individual"7.

A fisioterapia, desde o início de sua história em 1929 com a criação do $1^{\circ}$ Curso técnico de Fisioterapia na Santa Casa de Misericórdia de São Paulo, motivada pelo grande número de portadores de Poliomielite e crescimento de casos de acidentes de trabalho, passou por várias mudanças. Em 1951, a fisioterapia ainda era um curso técnico com a duração de um ano. De 1963 até 1983, permanecia vigente no Brasil um currículo mínimo estabelecido pelo Conselho Federal de Educação, que considerava ainda o fisioterapeuta como auxiliar do médico com uma formação mínima de apenas três anos. A partir de 1983 até o ano de 2001, esteve 
em vigência o novo currículo mínimo, que previa a formação em um período mínimo de quatro anos e máximo de oito anos, com carga horária mínima de três mil duzentas e quarenta horas ${ }^{4}$.

O plano diretor da reforma do estado de 1995 situa as Universidades e Instituições de pesquisa como não exclusivos do estado e "competitivos" e o sugerido pelo World Bank em documento redigido em 1998, que definia o ensino superior como um bem antes privado que público, espécie de quase mercadoria no quase mercado educacional, além de incluir os serviços educacionais na agenda de serviços comerciais a serem regulamentados pela Organização Mundial do Comercio $(\mathrm{OMC})^{8}$.

Chauí ${ }^{9}$ traz à luz a discussão sobre a reforma do estado onde o mercado é portador de racionalidade sócio-política e agente principal do bem-estar da república, este pressuposto leva a colocar direitos sociais como a saúde, educação e cultura no setor de serviços definidos pelo mercado ${ }^{10}$.

Paralelo a isso, em 19 de fevereiro de 2002 houve mudança na estrutura curricular vigente do Curso de Graduação em Fisioterapia, contemplando na nova estrutura a formação do egresso generalista, humanista, crítico e reflexivo, capacitado a atuar em todos os níveis de atenção à saúde, com base no rigor científico e intelectual. O debate sobre a necessidade dos profissionais da saúde repensarem suas práticas intensificou-se com a aprovação destas novas Diretrizes. No que tange as competências e habilidades, como por exemplo, no artigo $5^{\circ}$ :

II - atuar em todos os níveis de atenção à saúde, integrando-se em programas de promoção, manutenção, prevenção, proteção e recuperação da saúde, sensibilizados e comprometidos com o ser humano, respeitando-o e valorizando-o; e em Parágrafo único. A formação do Fisioterapeuta deverá atender ao sistema de saúde vigente no país, a atenção integral da saúde no sistema regionalizado e hierarquizado de referência e contra referência e o trabalho em equipe.

O Ministério da Saúde reviu as Diretrizes Curriculares dos Cursos de Graduação em Saúde pela constatação de que o modelo pedagógico tecnicista e especializado vigente não formaria profissionais com perfil, competências e habilidades necessárias para as mudanças propostas no setor. Dessa forma, a formação dos profissionais de saúde, até então estruturada sob um modelo pedagógico fragmentado, com formação tecnicista e especializada, com o ensino baseado na transmissão do conhecimento, tendo o professor como principal fonte de informação e o aluno como sujeito passivo nesse processo, torna-se obsoleta e ineficaz diante das transformações no setor saúde ${ }^{11}$.

Os pressupostos éticos e as diretrizes curriculares da formação superior, ao falarem da integralidade da atenção à saúde como parâmetro primordial para a ação e ao elegerem a interdisciplinaridade como paradigma fundamental da construção dos saberes e fazeres nos obriga a uma reflexão profunda sobre as estratégias que estão sendo utilizadas para a formação profissional.
As novas Diretrizes solicitam que a estrutura curricular garanta a prática profissional do fisioterapeuta na Atenção Básica. As Diretrizes apontam para a necessidade de a Fisioterapia responder às demandas do Sistema Único de Saúde (SUS) solicitando uma prática profissional interdisciplinar. Desde sua origem, o fisioterapeuta teve suas ações vinculadas a práticas curativas e individualizadas, relacionadas a disfunções físico-funcionais originadas por algum tipo de patologia e no âmbito da reabilitação ${ }^{12}$.

De acordo com essas Diretrizes, espera-se que todos os cursos de graduação organizem seus currículos proporcionando a formação de um profissional generalista, humanista, crítico e reflexivo, com habilidades e competências para atuar em todos os níveis de atenção à saúde ${ }^{12}$.

A proposta das diretrizes sugere transformar a formação e a prática do fisioterapeuta ao inserir a profissão no campo da prevenção e promoção da saúde. Ocorrendo uma busca pela ressignificação dos antigos valores que nortearam a prática profissional nos níveis secundários e terciários de atenção à saúde, imersos apenas no âmbito da reabilitação, em que a recuperação do "corpo biológico" constitui-se no seu grande objeto de trabalho. As diretrizes tentam mostrar que o que era suficiente como campo de atuação para a Fisioterapia em sua origem não se justifica nos dias atuais.

A Fisioterapia, ao buscar a integralidade amplia seu campo de ação, pois redimensiona o processo de reabilitação, passando a considerar as condições sociais do paciente na definição de sua proposta de intervenção. Seu olhar avança para além da condição clínica do paciente e para além do uso apenas de técnicas fisioterapêuticas, para além do espaço do ambulatório, da clínica ou do consultório, para além da doença, incorporando em suas ações uma visão multidimensional e interdisciplinar de saúde ${ }^{13}$.

Em 2007, as Escolas de Ciências da Saúde de uma Universidade da rede privada e de capital internacional aqui estudada propuseram grandes mudanças nas estratégias de ensino, buscando um aprendizado baseado nas metodologias ativas, currículos integrados ancorado na interdisciplinaridade e inserção de novas tecnologias educacionais. A proposta deste modelo seguiu um padrão já adotado pela Rede internacional que adquiriu a Universidade em questão.

Após oito anos de implantação, vemos a necessidade de um olhar mais atento ao que tange o embasamento dos professores em torno da integralidade, mas principalmente na busca de um currículo construído entre os pares, onde a integralidade de atenção à saúde dialogue com os preceitos da universidade.

A Pró Reitoria da universidade, em 2009, instituiu uma Coordenadoria de Desenvolvimento Educacional, que, desde então, tornou-se responsável pelo Programa de Capacitação Docente e Aprimoramento Acadêmico dos estudantes. As ações voltadas aos docentes concentram-se no Programa de Formação e Aperfeiçoamento Docente, setor da Universidade responsável pela indicação de cursos presenciais e online. Este programa estruturou-se para promover ações de capacitação do docente, no que 
se refere à didática e à atuação no Ensino Superior. Entre os objetivos do programa estão: pesquisar e aplicar estratégias metodológicas adequadas ao Ensino Superior; criar um espaço de reflexão crítica sobre a prática docente na sala de aula, visando melhorá-la e incentivar o orientar ações pedagógicas colaborativas entre docentes, para desenvolver um grupo coeso e com objetivos comuns centrados no desenvolvimento acadêmico do estudante.

Um dos autores que embasa a formação e aperfeiçoamento docente utilizado pela equipe do programa de aperfeiçoamento é Philippe Perrenoud, sociólogo suíço, um dos principais teóricos da pedagogia diferenciada, para Perrenound ${ }^{14}$, o papel mais importante da escola não é transferir conteúdos, mas desenvolver competências.

Perrenound ${ }^{14}$ chama de competência a capacidade de um sujeito de mobilizar o todo ou parte de seus recursos cognitivos e afetivos para enfrentar uma família de situações complexas. Pensar competências significa pensar a sinergia de recursos cognitivos e afetivos diversos para enfrentar um conjunto de situações que apresentam analogias de estrutura ${ }^{15,16}$. A noção de competência oscila entre uma concepção geral, separada de qualquer contexto identificável, e uma concepção muito limitada, que assimila a competência a um saber-fazer preciso em situações bastante específicas.

Em Ensinar: agir a urgência, decidir na incerteza, Perrenound ${ }^{15}$ diz que o estudo sobre competências não progride de forma linear e discute sobre as práticas pedagógicas, com as competências como pano de fundo. Neste sentido, o desafio é criar a instituição capaz de pensar de forma sistêmica, no sentido de pensar em sua complexidade interna e de suas dependências externas, construindo uma visão de conjunto de seu funcionamento e de seus ambientes, bem como propor linhas de ações coerentes. Para isso, é necessário haver lugares onde seja possível conversar, ações regulares em que se possa praticar um trabalho cooperativo sobre os problemas de fundo. O início de uma cultura comum é o reconhecimento das divergências. Cooperar não significa estar de acordo em tudo, mas saber gerenciar os desacordos.

Outro ponto importante a ser levado em conta são as dificuldades do professor em seu papel de fazer desabrochar os indivíduos e os integra-los na sociedade e sua fidelidade ao mandato recebido, onde ocorre uma tensão intransponível. Encontrar o equilíbrio estável é ainda mais difícil com a incoerência ou a hipocrisia das políticas educacionais e das práticas institucionais, tornando a docência um jogo entre a razão e a paixão. É preciso captar a natureza profunda desta complexidade para não se enganar sobre a natureza das competências. Perrenound ${ }^{14,15}$ diz que ensinar é enfrentar a complexidade, compara as competências do professor com as habilidades do malabarista ou do piloto de Fórmula 1 tanto quanto diretores de escola; ambos têm que enfrentar as mesmas contradições, pois parte da complexidade assumida pelo diretor da escola influencia as condições de trabalho do professor e, por fim, porque a profissão de educador é cada vez menos uma prática individual e também é exercida na escala da equipe pedagógica e do estabelecimento de ensino.

A competência consiste em identificar e resolver problemas complexos, navegando entre valores contraditórios e enfrentando conflitos internos e intersubjetivos. Nas competências dos professores, a capacidade de tomar consciência, de explicitar e descrever em julgar é essencial porque somente assim será possível trabalhar aberta e coletivamente com os verdadeiros problemas ${ }^{14-16}$.

Permitir que os professores se apropriassem de seus saberes, já que as instituições de formação dispensam saberes e avaliam seu domínio fora de qualquer contexto de ação por meio de exames e concursos e propõem que a formação dos professores seja trabalhada de acordo com três eixos complementares - à saber: reorganizar, tematizar os saberes eruditos em função dos limites e das exigências práticas; identificar as competências efetivas dos professores novatos ou veteranos, analisar o habitus profissional em todos os seus componentes; teorizar e valorizar os saberes provenientes da experiência, fazê-los circular, confrontá-los entre si, relacioná-los com os saberes eruditos ${ }^{14-16}$.

\section{MÉTODOS}

Realizou-se um estudo por meio da Pesquisa-Ação, tendo como cenário a intersecção entre três pontos fundamentais para a mudança da Matriz curricular da graduação em Fisioterapia em uma Universidade Privada, no caráter formador: pelas mudanças nas diretrizes curriculares, o olhar nas mudanças do SUS, por meio das redes de atenção e a integralidade de atenção à saúde, com um currículo baseado em competências. A investigação levou em conta a subjetividade, trabalhando com o universo de significados, motivos, aspirações, crenças, valores e atitudes, o que corresponde a um processo profundo das relações humanas.

A pesquisa-Ação, é a “identificação de estratégias de ação planejada que são implementadas e, a seguir, sistematicamente submetidas a observação, reflexão e mudança"17-19.

O instrumento para a coleta de dados foi à gravação dos encontros docentes e posteriormente a análise dos discursos/ conteúdos.

A análise de conteúdo tem intuito de realizar deduções lógicas e justificadas sobre a origem das mensagens. A proposta é uma divisão de etapas, organizada em três fases:

1. pré-análise, na qual se compreende a organização do material ao ser analisado por meio de leitura fluente, seleção do documento, formulação de hipótese e objetivos e elaboração dos indicadores;

2. exploração do material, na qual este é codificado e são definidas as categorias de análise, rubricas ou classes e a identificação das unidades de registro e unidades de contexto dos documentos. Nesta fase, cada elemento deve ser classificado em uma categoria; e

3. a terceira e última etapa consiste no tratamento dos resultados, inferência e interpretação. Nesta etapa, ocorre a condensação e o destaque das informações para análise, culminando nas 
interpretações inferenciais; é o momento da intuição, da análise reflexiva e $\mathrm{crítica}^{18,20}$.

Cada um dos doze professores foi identificado como sujeito ( 1 , $2,3, \ldots, 12)$ e as informações pertinentes a cada sujeito foram descritas: por que da adesão ao projeto, tempo de docência nesta universidade e outros vínculos de emprego.

Este estudo foi aprovado pelo Comitê de Ética em Pesquisa da UAM (CAAE 02458712.9.1001.5492).

\section{RESULTADOS E DISCUSSÃO}

Desde que a Universidade privada da cidade de São Paulo passou a fazer parte de uma rede de capital internacional, em 2005, muitas mudanças ocorreram gradativamente tanto no contexto Institucional quanto acadêmico. Em 2006, foi iniciada a implantação de novo modelo acadêmico proposto pela rede internacional que foi gradativamente sendo inserido na escola de saúde. No início de 2008, após um planejamento acadêmico, foram implantados, no início de todos os semestres letivos, treinamentos para os docentes com uma série de aplicações e vivências sobre metodologias ativas de ensino, com Works shops, palestras e práticas em simulação, bodypaintig, bodyproject, problem basic learn (PBL), utilização de diversos softwares de anatomia e fisiologia, team basic learn (TBL), estudos de caso, power lab, metodologias de avaliação, entre outros. Todos os docentes assistiram palestras com especialistas na área de metodologias ativas, que mostravam o novo modelo de ensino para o século XXI, por meio da "ensinagem", ou seja, o ensino sincrético, afetivo, cognitivo e psicomotor. Desde então, ao longo dos últimos anos, os treinamentos ocorrem durante duas semanas a cada início de semestre, para todos os professores da Universidade, sempre com propostas de aprofundamento dos temas, novos palestrantes e treinamento, fóruns docentes e novos cursos sobre estrutura humana e simulação, com desdobramentos nos cenários e debriefing.

O corpo de docentes que compõem o núcleo específico do curso de fisioterapia desta Universidade conta com 12 professores com tempo mínimo na docência nesta Universidade de quatro anos e máximo de 16 anos, todos passaram pelos treinamentos propostos e foram convidados a participar do novo desenho do curso, da composição de uma nova matriz curricular em 2007 com modificações em 2010 e 2012, para atender as novas exigências do MEC, e a última versão em 2013-1, que é utilizada até o presente momento. Esta matriz teve um direcionamento do departamento pedagógico da universidade a partir das novas regras impostas pela Universidade com blocos curriculares e parte do currículo composto por disciplinas a distância (EAD) em consonância com as novas regras internacionais.

Com base nessas mudanças, foram confeccionados os planos de ensino e planos de aula pelas equipes específicas dos docentes de cada uma das disciplinas que, desde então, são revistos semestralmente. Posto isso, é evidente que todos os envolvidos no processo sabiam das dificuldades em atender as novas propostas metodológicas e encontraram (e ainda encontram) muitos obstáculos. Diante dessa dificuldade, o grupo de docentes deliberou as estratégias para o início dos trabalhos. Ao gestor couberam articular formas de empoderar a equipe de professores do curso sobre a nova forma de ensinar - esse foi o maior desafio. De 2013 a 2015, foram realizadas reuniões semanais para discussões das mudanças do currículo baseado em competências, buscando um currículo menos conteudísta e mais abrangente, no sentido de utilizar conceitos transversais como norteadores para práticas fisioterapêuticas relacionados a busca do conceito cinético funcional na sua forma mais ampla, pautados na busca do olhar integral do ser humano.

Como se deliberou pela construção do currículo a partir da Pesquisa-Ação, o primeiro tema discutido foi identificado, no grupo, como primeira dificuldade: qual é o fisioterapeuta que esta instituição deseja formar. Todos os documentos legais foram levantados, entre eles o referencial nacional de procedimentos fisioterapêuticos (Resolução $n^{\circ} 428$ de 08 de julho de 2013), que estabelece as mudanças no código de ética e deontologia da Fisioterapia, o Referencial Nacional de honorários da fisioterapia além de inúmeros textos e artigos de diversos autores, entre eles Perrenoud ${ }^{14-16}$ e Morin ${ }^{21}$.

Neste processo, o papel da coordenação do curso foi de facilitador das discussões, dando voz aos pares e buscando consenso entre as opiniões individuais e experiências vividas nos últimos dezessete anos, tempo que o curso de Fisioterapia desta Universidade particular e internacional existe, desde o início de sua primeira turma. Os professores receberam textos e artigos sobre integralidade, currículos por competências e houve muitos momentos de discussão para um melhor entendimento do trabalho a ser realizado.

O trabalho iniciou com a definição dos eixos norteadores na busca de um currículo baseado em competências. Após muitas discussões, ficaram estabelecidos três eixos, que são: Fisioterapia Hospitalar, Fisioterapia Ambulatorial e Fisioterapia Comunitária. Decididos os três eixos, partimos para as competências de cada eixo, chegando a um consenso que duas competências seriam suficientes para serem trabalhadas em cada eixo.

A primeira competência do eixo hospitalar foi realizar avaliação clínica e cineticofuncional dos sistemas corporais com ênfase nos sistemas cardiorrespiratório e osteomioarticular de pacientes em diferentes setores hospitalares e em diferentes momentos do ciclo vital e para esta competência foram traçados sete objetivos. A segunda competência foi definir a conduta fisioterapêutica, escolhendo e utilizando os recursos fisioterapêuticos manuais e instrumentais para a prática hospitalar, também levando em consideração o estado funcional e as possíveis disfunções do paciente hospitalizado. Para esta competência, foram traçados cinco objetivos de ensino. A partir da identificação destes objetivos, foram elencadas as unidades curriculares onde estes conteúdos são abordados e os objetivos de aprendizagem em cada momento do curso.

As reuniões semanais ocorreram no periodo de maio de 2013 a fevereiro de 2015, quando foi finalizado o documento norteador 
das competências necessárias para a formação do fisioterapeuta. Concluído o documento, o próximo passo é a inserção das competências nos planos de ensino e planos de aula, com previsão para o primeiro semestre de 2016.

Analisando o percurso desde o início deste projeto, é importante lembrar que a concepção do projeto pedagógico do curso de fisioterapia tem como base a integralidade de atenção à saúde, bem como o desenvolvimento das competências com o olhar para as redes de atenção à saúde. $\mathrm{O}$ instrumental utilizado para que as competências sejam inseridas no contexto de aulas são as metodologias ativas e a estratégia utilizada para a construção é a Pesquisa-Ação.

A maior dificuldade para que o projeto seja de fato posto em prática e de forma viável, ou seja, que se possa ofertar um curso de fisioterapia que forme profissionais com base na integralidade de atenção à saúde, é necessário que todas as partes envolvidas no processo estejam alinhados. Partes estas que se resumem a corpo docente, corpo discente, instituição privada, mercado de trabalho e legislação da profissão.

Devido a uma "confusão" conceitual, no curso de fisioterapia, prevalecia entre os docentes um olhar sobre a atenção secundária e terciária da saúde. Com o resultado prévio, o objetivo passou a ser identificar quais os fatores comprometem a incorporação dos ideários.

Em 2011, a fisioterapia realizou a primeira avaliação dos docentes para observar as representações sociais em torno de dois objetos, a interdisciplinaridade e a integralidade, identificando distorções e dificuldades na compreensão dos conceitos e mostrando a necessidade de novas medidas para o aperfeiçoamento dos conceitos e ações. A estruturação de uma nova matriz curricular que atendesse a estas necessidades foi necessária. Foi um desafio criar uma matriz que atendesse a todas as necessidades, mercado, instituição privada e o comprometimento com uma formação sólida e baseada na integralidade.

O ponto de partida foi o corpo docente, que foi formado em um modelo tradicional e que vem sendo, ao longo dos últimos anos, desde a implantação do novo projeto institucional, "treinado" pela instituição a desenvolver suas aulas no novo modelo inserindo as novas metodologias de ensino, com novas dinâmicas de aula e com a possibilidade de ser pouco compreendido pelos discentes, que esperam uma aula tradicional, com apresentação de slides e longas aulas teóricas. Os professores participaram de todas as formações sugeridos pela Universidade, que ocorreram e ainda ocorrem a cada início de semestre, onde o professor participa de diferentes Works shops, palestras, treinamentos práticos, trocas de experiências entre professores de todos os cursos de saúde. Desse modo, todos buscaram juntos formas de utilizar as metodologias ativas de ensino. Este modelo utiliza seguintes estratégias: Educação para Adultos; Aprendizagem significativa; Aprendizagem baseada em competências, habilidades, valores e atitudes; Inserção prática desde o princípio, supervisionada, mensurada e assistida; Enfoque de novas demandas de conhecimento; Novas Tecnologias Educativas;
Metodologias Ativas de Ensino e Aprendizagem; Avaliação como feedback do processo de ensino-aprendizagem. Ao discutirmos o atingimento dos objetivos propostos nas formações, se faz necessário pensar sob a ótica da promoção de saúde. Por um lado, o professor, durante todo o período de treinamento, é instrumentalizado para cumprir as tarefas propostas por outro que nem sempre está subsidiado pelas perspectivas teóricas e práticas que a justificam.

De forma paralela, parte da estratégia utilizada pela equipe especifica do curso de fisioterapia foi a busca por um currículo que fosse realmente concebido com base na integralidade de atenção. Para isso, foram feitas discussões semanais entre o corpo específico do curso de fisioterapia, com leituras textuais frequentes, discussões sobre qual o perfil do profissional que a universidade quer formar, que o mercado pode absorver e que nós, enquanto fisioterapeutas e educadores podem formar um fisioterapeuta de fato completo.

Entre os autores que embasaram as discussões, trouxe muitas contribuições ao descrever uma estreita relação entre inteligência e afetividade, que ele chama de eixo intelecto-afeto, onde a capacidade de emoções é indispensável ao estabelecimento de comportamentos racionais. Para ele, o conhecimento científico não pode tratar sozinho dos problemas epistemológicos, filosóficos e éticos ${ }^{20,21}$.

Manter a racionalidade significa elaborar teorias coerentes, verificar o caráter lógico da organização teórica, compatibilidade entre ideias. Morin descreve a possibilidade de a racionalidade ser pervertida e se tornar racionalização, onde o sistema lógico é perfeito, porém, nega-se a contestação, argumentação e verificação empírica. Daí vem a necessidade de reconhecer na educação do futuro um princípio de incerteza racional, a racionalidade corre um risco constante, caso não mantenha vigilante autocritica quanto a cair na ilusão racionalizadora ${ }^{20,21}$.

O perfil do fisioterapeuta formado pela Universidade deve contemplar uma visão crítica e problematizadora da natureza social do processo saúde-doença, sem deixar de contemplar a formação técnica e científica, que deve estar expressa tanto no currículo oferecido pelo curso quanto em sua opção metodológica. Outro desafio é romper com os modelos disciplinares rígidos na busca do aperfeiçoamento da formação do fisioterapeuta, numa integração de diferentes conhecimentos, áreas disciplinares e profissionais ${ }^{22,23}$.

Analisando as falas dos professores que compõe o núcleo específico do curso, ao longo de 11 momentos de discussões, com duração mínima de 28 minutos e máxima de 77 minutos, entre os meses de maio de 2013 e março de 2015, com a proposta de discutir as competências do curso de fisioterapia, segue as falas que surgiram em torno de assuntos recorrentes, ideário básico da integralidade, dialogando com a corporação em que o grupo está inserido, ou seja, um local de trabalho que fica entre a visão do lucro e da responsabilidade social.

Quando foram discutidos os conceitos em torno de integralidade, observamos as seguintes categorias: 


\section{Categoria: A integralidade ainda não é uma realidade no cenário nacional}

A ideia acima pode ser observada no Sujeito 1:

faltam ferramentas para agir na atenção primária no nosso país, trabalhar na necessidade do indivíduo de forma primária só é possível em países desenvolvidos.

Sujeito 4 afirma que

é necessário primeiro entendermos melhor o conceito de integralidade. Há muita confusão conceitual, precisamos estudar mais, ler mais, para sermos bons multiplicadores.

Estudos apontam a necessidade de ampliar a base conceitual da integralidade e a ação multiprofissional, buscando maior potência de cada ação ${ }^{13,18}$. É grande a necessidade de discussões e reflexões sobre a ativação da integralidade no processo de trabalho das equipes multiprofissionais na saúde coletiva, com bases na teoria da complexidade de Morin e na lógica transdisciplinar de Basarab Nicolescu ${ }^{4,20}$.

O Sujeito 10 comenta que,

Dentro das [unidades básicas de saúde] UBSs, não se trabalha saúde primária, é fato que os usuários querem e precisam de atendimento fisioterapêutico.

Arruda $^{23}$ diz que dentro os serviços de saúde possuem regras travadas e burocratizadas, que impedem o movimento dinâmico e integrado do cuidado em saúde priorizado peas redes de atenção à saúde (RAS)

\section{Categoria: $\mathrm{Na}$ fisioterapia persiste o modelo medicalizado ou biologicista}

Essa ideia pode ser observada na fala do Sujeito 2, quando afirma que

A fisioterapia fica entre o modelo medicalizado e tomar a decisão sobre a nova fisioterapia como instrumento empoderado pelo fisioterapeuta. Um modelo ideal construído a partir de competências, com discursos heterogêneos, dependendo do país onde estão inseridas as competências diferem de acordo com os objetivos da corporação.

Para o Sujeito 8,

A fisioterapia ainda tem um olhar clinico, fica no limbo entre o modelo medico e um novo modelo.

O Sujeito 12 ainda lembra que

o modelo de clinica se modernizou, mas a lógica é a mesma, o fisioterapeuta atuando na reabilitação e cura de doentes.
Autores $^{24-26}$ confirmam este cenário quando, em seus estudos, apontam que o modelo de formação adotado pela profissão é curativo, reabilitador privatista, inadequado à nova realidade epidemiológica e ao atual modelo de atenção à saúde.

\section{Categoria: A construção de um currículo baseado por competências}

Para o Sujeito 2

a produtividade no modelo Europeu tem o foco no homem, modelo americano tem o foco no lucro, a universidade indica textos de autores europeus (Perrenaund).

O Sujeito 1 questiona:

A universidade segue um modelo americano mas escolhe textos europeus para falar de competências, será que a instituição entende esta ambiguidade como tensão docente?

Segundo o Sujeito 9,

Para funcionar, o professor precisa estar seguro do manejo do material novo.

Perrenoud ${ }^{15,16}$ pensa competência como capacidade de analisar a situação, compreender qual o problema e pensar em soluções e estratégias a serem adotadas, com quem contar, onde há recursos. Portanto, pensar competências é pensar em situações complexas.

De acordo com o Sujeito 5:

este modelo permite que revisite os conteúdos ao longo de todo o curso.

Segundo o Sujeito 10,

já detectamos que muitos conteúdos não foram vistos, somente revisando os planos de ensino de forma geral. Podemos aparar muitas falhas a partir do currículo por competências.

O Sujeito 3 afirma que

pesquisa em saúde, ética, saúde mental e gestão são conteúdos transversais em um currículo baseado por competências.

O Sujeito 4 comenta que,

para se chegar aos eixos, é necessário pensar no perfil do profissional fisioterapeuta, ou seja, que fisioterapeuta queremos formar?

$\operatorname{Santos}^{27}$ lembra que a complexidade busca interpretações do significado do complexo, que envolve terminologias como transdisciplinaridade, multidisciplinaridade, imbricadas com as questões da saúde. 


\section{Categoria: A utilização das metodologias ativas e as dificuldades no dia a dia}

Segundo o Sujeito 3,

a simulação é hoje focada nas habilidades, possibilidade do uso do cenário é interessante, mas há dificuldades de interpretar a construção ativa de alunos. Nem todos os professores tem formação para estas interpretações.

O Sujeito 11 aponta que

Debriefing dos cenários não serve se quem interpreta não tem instrumentos para analisar situações emocionais complicadas.

Para o Sujeito 2:

A saúde coletiva como campo de saber dá conta de ajudar nas interpretações de situações do dia a dia na utilização das metodologias ativas.

As metodologias ativas utilizam a problematização como uma das estratégias de ensino, com objetivo de motivar o discente pois diante do problema ele se detém, examina, reflete, relaciona sua história e passa a resinificar suas descobertas ${ }^{25}$.

\section{Categoria: As mudanças não surgem da comunidade acadêmica, mas são impostas verticalmente}

Esta categoria foi recorrente de acordo com o Sujeito 4:

A demanda da reorganização da grade curricular por competências foi de cima para baixo, ou seja, imposta.

\section{O Sujeito 7 sente que}

São tantas mudanças, não há nada estável, nunca está bom, sempre querem mais.

O Sujeito 9 lembra que:

Chamo isso de re-trabalho, são tantas mudanças que estamos sempre perdendo tempo com novas formas de fazer a mesma coisa.

\section{Para o Sujeito 2}

As demandas de mudança na educação estão relacionadas às constantes mudanças no cenário econômico do país, todos os atores da educação estão envolvidos e precisam estar atentos.
O ideário de flexibilização curricular presente na elaboração das diretrizes curriculares para os cursos de graduação está associado intimamente à reestruturação produtiva do capitalismo global, particularmente à acumulação flexível e à flexibilização do trabalho ${ }^{11,28-30}$.

\section{Categoria: A internacionalidade e a Universidade Internacional}

$\mathrm{Na}$ fala do Sujeito 6:

as práticas internacionais são pouco aproveitadas entre os docentes, pois não há incentivo financeiro para viabilizar o intercambio.

Segundo o Sujeito 1:

Somos internacionais mas não podemos trocar experiências em outros países sem que tenhamos que pagar por isso.

Para o Sujeito 2,

A integralidade dialogando com a corporação, que tem a lógica de fins lucrativos e da responsabilidade social, neste cenário é que devemos atuar.

O Sujeito 4 questiona

como sensibilizar a corporação a respeitar a os princípios e as necessidades da integralidade?

Para o Sujeito 2,

No Brasil, o próprio cenário já convida para a alteridade, já que é um país miscigenado, um caldeirão cultural, que permite boas possibilidades de intercambio.

Determinada pelas diretrizes economicistas, a sociedade se transforma em espaço de intercâmbios de natureza mercadológica ${ }^{1}$.

Conclui-se, assim, de acordo com as categorias acima e de acordo com as falas dos docentes, que há muito a se explorar na implantação de um currículo integrado. Ao comparar os autores, fica mais claro que as angústias e dificuldades dos docentes neste percurso fazem parte de um processo já identificado em muitas literaturas. No entanto, a exploração deste tema e a implantação do currículo nos permite sempre novas inserções, com possibilidade de ouvir e empoderar os docentes neste processo, que são essenciais para o sucesso de um currículo baseado em competências. 


\section{REFERÊNCIAS}

1. Sobrinho JD. Universidade e novos modos de produção, circulação e aplicação do conhecimento. Avaliação. 2014;19(3):643-62. http://dx.doi.org/10.1590/S1414-40772014000300007

2. Brasil. Presidência da Republica. Casa Civil. Decreto-lei no 938, de 13 de outubro de 1969. Disponível em: http://www.planalto. gov.br/ccivil_03/decreto-lei/1965-1988/Del0938.htm. Acesso em: 29 set. 2015

3. Almeida ALJ, Guimarâes RB. O lugar social do fisioterapeuta brasileiro. Fisioter Pesqui. 2009;16(1):82-8. http://dx.doi.org/10.1590/S1809-29502009000100015

4. Rebellato JR, Botomé CF. Fisioterapia no Brasil. 2.ed. São Paulo: Manole, 2001

5. Rodrigues JM, Peixoto Junior CA. Reflexões sobre conceitos afirmativos de saúde e doença nas teorias de George Canguilhem e Donald Winnecott. Physis. 2014;24(1):291-310.

http://dx.doi.org/10.1590/S0103-73312014000100016

6. Camargo Jr. KR. As armadilhas da "concepção positiva de saúde". Physis. 2007;17(1):63-76. http://dx.doi.org/10.1590/S0103-73312007000100005

7. Canguilhem G. O normal e o patológico. $5^{a}$.ed. Rio de Janeiro: Forense Universitária, 2000

8. Haddad AE. A trajetória dos cursos de graduação na área de saúde: 1991-2004. Brasília: Instituto Nacional de Estudos e Pesquisas Educacionais Anísio Teixeira; 2006.

9. Chauí M. A universidade pública sob nova perspectiva. Rev Bras Educ. 2003;(24):5-15 http://dx.doi.org/10.1590/S1413-24782003000300002

10. Sguissardi V. Reforma universitária no Brasil-1995-2006: precária trajetória e incerto futuro. Educ Soc. 2006;27(96):1021-56.

11. Schmidt LA. Os cursos de fisioterapia no Paraná frente aos conceitos contemporâneos de saúde. Dissertação (Mestrado) Centro de Ciências da Saúde, Universidade Estadual de Londrina, Londrina, 2002.

12. Brasil. Instituto Nacional de Estudos e Pesquisa (INEP). Pesquisas Educacionais Anísio Teixeira. Relatórios síntese: 2010. Disponível em: http://portal.inep.gov.br/web/guest/enade/ relatorio-sintese-2010. Acesso em 12 ago. 2014.

13. Brasil. Conselho Nacional de Educação. Câmara de Educação Superior. Resolução n. 4/2002 CNE/CES, 19 fev. 2002. Diário oficial da união. Brasília: 2002; p.11.

14. Perrenoud P. Ensinar: agir na urgência, decidir na incerteza. $2^{\mathrm{a}}$.ed. Porto Alegre: Artmed, 2001.

15. Perrenoud P. Construir as competências desde a escola. Porto Alegre: Artes Médicas Sul, 1999

16. Perrenoud P. 10 novas competências para ensinar. Porto alegre: Artmed, 2000
17. Grundy SJ, Kemmis S. Educational action research in Australia: the state of the art. Geelong: Deakin University Press, 1982.

18. Tripp D. Pesquisa-ação: uma introdução metodológica. Educação e Pesquisa. 2005;31(3):443-66.

19. Cecilio LCO, Andreazza R, Carapinheiro G, Araújo EC, Oliveira LA Andrade MGG, et al. A Atenção Básica à Saúde e a construção das redes temáticas de saúde: qual pode ser o seu papel? Ciênc Saúde Coletiva. 2012;17(11):2893-902. http://dx.doi.org/10.1590/S1413-81232012001100006

20. Bardin L. Análise de conteúdo. Lisboa: Edições 70; 2006.

21. Morin E. Os sete saberes necessários à educação do futuro $2^{a}$.ed. São Paulo: Cortez, 2000

22. Ceccim BR, Feuerwerker LCM. Mudanças na graduação das profissões da saúde sob o eixo da integralidade. Cad Saúde Pública. 2004;20(5):1400-10. http://dx.doi.org/10.1590/S0102-311X2004000500036

23. Severo SB, Seminotti N. Integralidade e transdisciplinaridade em equipes multiprofissionais na saúde coletiva. Ciênc Saúde Coletiva. 2010;15(supl.1):1685-98 http://dx.doi.org/10.1590/S1413-81232010000700080

24. Arruda C, Lopes CGR, Koerich MHAL, Winck DR, Meirelles BHS Mello ALSF. Redes de atenção à saúde sob a luz da teoria da complexidade. Esc Anna Nery. 2015;19(1):169-73. http://dx.doi.org/10.5935/1414-8145.20150023

25. Bispo Junior JP. Formação em fisioterapia no Brasil: reflexões sobre a expansão do ensino e os modelos de formação. Hist Ciênc Saúde-Manguinhos. 2009;16(3):655-68. http://dx.doi.org/10.1590/S0104-59702009000300005

26. Bispo Junior JP. Fisioterapia e saúde coletiva: desafios e novas responsabilidades profissionais. Ciênc Saúde Coletiva. 2010;15(suppl.1):1627-36

http://dx.doi.org/10.1590/S1413-81232010000700074

27. Santos SSC, Hammerschmidt KSA. A complexidade e a religação de saberes interdisciplinares: contribuição do pensamento de Edgar Morin. Rev Bras Enferm. 2012:65(4):561-5. http://dx.doi.org/10.1590/S0034-71672012000400002

28. Mitre SM, Siqueira-Batista R, Girardi-de-Mendonça JM, Morais-Pinto NM, Meirelles CAB, Pinto-Porto C, et al. Metodologias ativas de ensino aprendizagem na formação profissional em saúde: debates atuais. Ciênc Saúde Coletiva. 2008;13(Sup2):2133-44. http://dx.doi.org/10.1590/S1413-81232008000900018

29. Brasil. Ministério da Saúde. Política de Educação e Desenvolvimento para o SUS: caminhos para a educação permanente em saúde pólos de educação permanente em saúde. Brasília: MS; 2004

30. Catani AM, Oliveira JF, Dourado LF. Politica educacional mudanças no mundo do trabalho e reforma curricular nos cursos de graduação no Brasil. Educ Soc. 2001;22(75):67-83. http://dx.doi.org/10.1590/S0101-73302001000200006 